AC ANNALS JOURNAL CLUB

\title{
The Big Picture on Antibiotics for Respiratory Infections
}

Ann Fam Med 2013;11:iii. doi:10.1370/afm.1519.

$\mathrm{T}$ The Annals of Family Medicine encourages readers to develop a learning community of those seeking to improve health care and health through enhanced primary care. You can participate by conducting a RADICAL journal club and sharing the results of your discussions in the Annals online discussion for the featured articles. RADICAL is an acronym for Read, Ask, Discuss, Inquire, Collaborate, Act, and Learn. The word radical also indicates the need to engage diverse participants in thinking critically about important issues affecting primary care and then acting on those discussions. ${ }^{1}$

\section{HOW IT WORKS}

In each issue, the Annals selects an article or articles and provides discussion tips and questions. We encourage you to take a RADICAL approach to these materials and to post a summary of your conversation in our online discussion. (Open the article online and click on "TRACK Comments: Submit a response.") You can find discussion questions and more information online at: http://www.AnnFamMed.org/AJC/.

\section{CURRENT SELECTION}

\section{Article for Discussion}

Meropol SB, Localio AR, Metlay JP. Risks and benefits associated with antibiotic use for acute respiratory infections: a cohort study. Ann Fam Med. 2013;11(2):165-172.

\section{Discussion Tips}

This large cohort study provides an opportunity to wear both our personal clinician and public health hats in balancing the risks of antibiotic resistance and side effects against the benefit of antibiotics for selected people with respiratory tract infections. The introduction and discussion of this article do a nice job of laying out the relevant issues.

\section{Discussion Questions}

- What are the study's research questions and hypotheses, and why do they matter?
- How does this study advance beyond previous research and clinical practice on this topic?

- How strong is the study design for answering the question?

- To what degree can the findings be accounted for by:

1. How patients were selected, excluded, or lost to follow-up?

2. How the main variables were measured?

3. Confounding (false attribution of causality because 2 variables discovered to be associated actually are associated with a 3 rd factor)?

4. Chance?

5. How the findings were interpreted?

- How were possible biases controlled for in analyses? How do the sensitivity analyses affect your confidence in the findings?

- What are the main study findings? What (if anything) surprised you?

- How comparable is the study sample to similar patients in your practice? What is your judgment about the transportability of the findings?

- In applying the findings to patient care, how do you weigh the different risks and benefits examined in this study? How about the societal and individual risks of antibiotic resistance (that were not examined by this study)?

- How might this study change your practice? Policy? Education? Research?

- Who are the constituencies for the findings, and how might they be engaged in interpreting or using the findings?

- What are the next steps in interpreting or applying the findings?

- What researchable questions remain?

\section{References}

1. Stange KC, Miller WL, McLellan LA, et al. Annals Journal Club: It's time to get RADICAL. Ann Fam Med. 2006;4(3):196-197. http:// annfammed.org/cgi/content/full/4/3/196. 